\title{
PENGEMBANGAN PERANGKAT PEMBELAJARAN MATEMATIKA MODEL KOOPERATIF TIPE STAD DENGAN MEDIA POWERPOINT ISPRING PADA MATERI JAJARGENJANG, LAYANG-LAYANG, DAN TRAPESIUM Di KELAS VII SMP
}

\author{
Endang Suprapti \\ Prodi Pendidikan Matematika \\ FKIP-UM Surabaya \\ email: endangumsurabaya@gmail.com
}

\begin{abstract}
The aim of this research are: to describe the process of development and instructional instruments of cooperative learning type STAD with Microsoft Power Point Ispring on topic parallelogram, the kite and trapezium at SMP Class Seven. The Subject of this research is SMP Muhammadiyah 13 Surabaya in class seven at year 2013-2014, tow parallel class are VII A an VII B.

The model of development teaching material for this research is use 4-D Thiagarajan's development instructional model. The development process consist of four phases, those are define, design, develop, and disseminate. Instructional instruments that developed are lesson plan, students work sheet, achievement test and the microsoft power point ispring media learning. The researches instrument are used validation's instructional instruments sheet, observational sheet of student's activities in learning, observational sheet of teacher ability to manage the instruction, and the quotioner of students responses.

The instructional instruments that has been developed by the next one will be seen whether already as instructional instruments that was good that is an equipment that could support learning process so as the aim that it was hoped could be reached and be equipment pembelajaran that was developed in accordance with the development procedure of instructional instruments and met (1) Valid that is has divalidasi by the expert and filled the minimal criterion valid. (2) was tested, by filling the criterion: (a) the teacher's capacity managed pembelajaran was classified as effective (b) the Activity of the student was classified as active (c) the positive Criterion for the student's response to pembelajaran and the completeness of studying results in a classical manner was reached (d) the results Test studied met valid, reliable and sensitive.

Based on the analysis in the development stage, was received by the conclusion that instructional instruments cooperative model mathematics the STAD type with the media Microsoft PowerPoint Ispring learning to material parallelogram, the kite and the trapezium in the SMP Muhammadiyah 13 VII classes filled the good criterion was based on results of the validation of the expert and results of the test that filled conditions that were determined that is, (1) the activity of the student during pembelajaran effective; (2) the teacher's capacity in managed learning process effective; (3) the student's response to pembelajaran active and the completeness of studying results in a classical manner was reached; and (4) the results test studied that was used sensitive, valid, and reliabel.
\end{abstract}

Key Word: Cooperative learning type STAD, Intructional instrumens, micorsoft powerpoint ispring media

\section{PENDAHULUAN}

Matematika memiliki salah satu ciri penting yaitu obyek abstrak sehingga kebanyakan siswa menganggap bahwa matematika itu sulit. Sifat abstrak obyek matematika tersebut merupakan salah satu penyebab sulitnya seorang guru 


\section{Endang Suprapti}

mengajarkan matematika sekolah. Seorang guru matematika harus berusaha untuk mengurangi sifat abstrak objek matematika itu sehingga memudahkan siswa menangkap pelajaran matematika di sekolah (Soedjadi, 2000:41-42). Dengan kata lain seorang guru matematika harus mengusahakan agar "fakta", "konsep", "operasi" ataupun "prinsip" dalam matematika terlihat konkret oleh siswa. Salah satu usaha agar konsep matematika terlihat konkret (dapat dibayangkan) adalah dengan menggunakan media atau alat peraga.

Belakangan ini penggunaan media semakin berkembang pesat, terutama di tingkat SMP penggunaan media komputer sudah dapat dilaksanakan. Dalam Kurikulum Satuan Tingkat Pendidikan (KTSP) 2006 dijelaskan untuk meningkatkan keefektifan pembelajaran, sekolah diharapkan menggunakan Teknologi Informasi dan Komunikasi (TIK) seperti komputer, alat peraga, atau media lainnya. Komputer mampu menampilkan berbagai komponen media, seperti video, gambar, teks, animasi, dan suara sehingga dapat merangsang lebih banyak indra. Melalui video dan gambar, dapat ditampilkan kejadian nyata yang berkaitan dengan materi yang dipelajari sehingga pembelajaran menjadi lebih kontekstual dan peserta didik lebih mudah memahami materi. Materi yang disajikan dengan animasi akan membantu pemahaman materi serta belajar menjadi lebih menarik.

Media pembelajaran berbasis komputer (aplikasi teknologi) yang dikembangkan dengan program komputer umumnya dikenal dengan ComputerAssisted Instruction (pembelajaran berbantuan komputer). Menurut Arsyad (2009:31), aplikasi tersebut apabila dilihat dari cara penyajian tujuan yang ingin dicapai meliputi: (a) tutorial (penyajian materi secara bertahap), (b) drill and practice (latihan untuk membantu siswa menguasai materi yang telah dipelajari sebelumnya, (c) permainan dan simulasi dan (d) Basis data (sumber yang dapat membantu siswa menambah informasi dan pengetahuan sesuai keinginan masingmasing). Dengan demikian dapat disimpulkan media pembelajaran berbantuan komputer adalah alat yang digunakan untuk mempermudah penyampaian materi pada saat kegiatan belajar mengajar.

Pengembangan media dengan menggunakan TIK seperti komputer tentunya memanfaatkan suatu softwere atau perangkat lunak untuk membuat animasi yang menarik dalam waktu yang cepat seperti Microsoft PowerPoint yang sering kita 
jumpai dalam program komputer. Microsoft PowerPoint merupakan program untuk membuat presentasi dengan fasilitas yang ada dapat digunakan untuk membuat media pembelajaran, program yang dihasilkan cukup menarik jika di gabungkan dengan menggunakan software Ispring Presenter yang dapat merubahnya menjadi media animasi dalam bentuk flash.

Penggunaan media atau alat peraga dalam pembelajaran dapat berjalan efektif jika guru dapat mengelola dengan baik proses pembelajaran di kelas. Oleh karena itu seorang guru harus dapat memilih dan menggunakan metode yang tepat dalam mengajar sehingga tercapai tujuan pembelajaran. Seperti yang diungkapkan oleh Trianto (2007:3) yaitu guru harus bijaksana dalam menentukan suatu model yang sesuai yang dapat menciptakan situasi dan kondisi kelas yang kondusif agar proses belajar mengajar dapat berlangsung sesuai dengan tujuan yang diharapkan.

Mengingat kemampuan siswa yang heterogen, tidak tertutup kemungkinan ada siswa yang tidak bisa menggunakan media berbantuan komputer dengan baik. Hasil penelitian yang dilakukan Hulten dan Devries (dalam Fikrati, Ama Noor, 2006:4) menunjukkan kerja kelompok membuat siswa bersemangat untuk belajar dan aktif untuk saling menampilkan diri atau berperan di antara teman-teman sebaya. Karena itu pelajaran dengan model kooperatif dapat memacu semangat siswa untuk saling membantu memecahkan masalah.

Model pembelajaran kooperatif merupakan suatu model pembelajaran yang mengutamakan adanya kelompok di mana setiap siswa yang ada dalam kelompok mempunyai tingkat kemampuan yang berbeda-beda dan jika memungkinkan berasal dari ras, budaya, suku yang berbeda. Selain itu, model pembelajaran kooperatif juga mengutamakan kerja sama dalam menyelesaikan permasalahan untuk menerapkan pengetahuan dan keterampilan dalam rangka mencapai tujuan pembelajaran. Dalam pembelajaran kooperatif dikembangkan diskusi dan komunikasi dengan tujuan agar siswa saling berbagi kemampuan, belajar berpikir kritis, menyampaikan pendapat, memberi kesempatan menyalurkan kemampuan, membantu belajar, menilai kemampuan dan peranan diri sendiri maupun teman lain.

Slavin (2008:12) mengemukakan gagasan utama Student TeamAchievement Divisions (STAD) adalah metode pembelajaran kooperatif yang 
paling sederhana, dan merupakan model yang paling baik untuk permulaan bagi para guru yang baru menggunakan pembelajaran kooperatif. Penelitian ini memilih pembelajaran kooperatif tipe STAD siswa bekerja bersama-sama dalam kelompok, saling membantu, saling berbagi ide dan berdiskusi untuk menyelesaikan materi atau tugas yang diberikan kepada siswa, sehingga siswa terlibat aktif dalam mengkontruksi pengetahuan yang akan dipelajarinya dan guru bertindak sebagai fasilitator. Pembelajaran tipe ini dapat dilaksanakan di dalam kelas dengan adanya kuis untuk mengetahui sejauh mana penguasaan siswa terhadap materi yang telah dipelajari bersama kelompoknya. Selain itu dengan adanya skor perkembangan dapat memotivasi siswa untuk saling memberi semangat dan saling membantu dalam menuntaskan materi yang dipelajari untuk memperoleh penghargaan kelompok.

Geometri merupakan salah satu cabang dari pelajaran matematika yang penting untuk dipelajari, karena geometri mencakup latihan berpikir logis, kerja yang sistematis, menghidupkan kreatifitas, serta dapat mengembangkan kemampuan berinovasi (Purniati, 2004). Geometri dipandang sebagai salah satu pokok bahasan yang cukup sulit karena geometri bersifat abstrak dan membutuhkan tampilan yang lebih konkrit (dapat dibayangkan) oleh siswa dalam proses pembelajarannya. Mengingat geometri bersifat abstrak dan untuk siswa dapat lebih mudah memahami dan menguasainya sangat diperlukan tampilan konsep geometri yang lebih konkrit (dapat dibayangkan) berupa obyek yang bisa memberikan tampilan yang dapat dibayangkan siswa sehingga dapat menarik minat dan motivasi siswa dalam belajar serta mudah dipahami siswa. Dengan demikian penggunaan alat peraga atau media yang dapat menampilkan secara visual dan interaktif bisa menjadi alternatif penyelesaian masalah ini.

\section{METODE PENELITIAN}

Penelitian ini tergolong penelitian pengembangan. Dalam hal ini penelitian pengembangan dilaksanakan untuk menghasilkan perangkat pembelajaran dengan media pembelajaran Microsoft PowerPoint Ispring model kooperatif tipe STAD pada jajargenjang, layang-layang dan tarpesium di SMP kelas VII. Adapun perangkat pembelajaran yang dikembangkan meliputi: Rencana Pelaksanaan 
Pembelajaran (RPP), Media Pembelajaran Microsoft Power Point Ispring, Lembar Kerja Siswa (LKS), Kuis dan Tes Hasil Belajar (THB).

Prosedur pengembangan yang digunakan untuk mengembangkan perangkat pembelajaran dalam penelitian ini, mengacu pada model yang dikemukakan Thiagarajan, Semmel dan Semmel (1974). Proses pengembangan instrumen ini terdiri dari empat tahap yaitu: Define (pendefinisian), Design (Perancangan), Develop (Pengembangan), dan Disseminate (penyebaran). Tahap ke-4 dari model tersebut yaitu tahap penyebaran (disseminate) tidak dilaksanakan karena keterbatasan waktu dan kemampuan penelti.

Dalam penenelitian ini, perangkat pembelajaran yang baik adalah perangkat pembelajaran yang dikembangkan sesuai dengan prosedur pengembangan perangkat pembelajaran dan memenuhi tujuan yang diharapkan sesuai dengan kriteria yang ditetapkan. Perangkat pembelajaran yang dimaksud antara lain RPP, Media Pembelajaran microsoft PowerPoint Ispring, LKS, Kuis dan THB. Beberapa aspek yang perlu diperhatikan dalam menyusun perangkat pembelajaran yaitu: (i) Valid, yaitu telah di validasi oleh ahli dengan memenuhi kriteria yang diadaptasi dari Prayitno (2008: 85) sebagai berikut: (1) Format Perangkat, meliputi: kejelasan pembagian materi, penomoran, daya tarik, kesesuaian antara teks dan ilustrasi, jenis dan ukuran huruf, pengaturan ruang. (2) Ilustrasi, meliputi: dukungan ilustrasi memperjelas konsep, keterkaitan secara langsung dengan konsep, kemudahan untuk dipahami. (3) Bahasa, meliputi: kebenaran tata bahasa, kesesuaian kalimat dengan tingkat pekembangan siswa, tidak mengandung makna ganda, kesederhanaan struktur kalimat, kejelasan petunjuk dan arahan, serta bahasa yang komunikatif.(4) isi, meliputi: kebenaran materi, bagian-bagian yang tersusun sistematis dan logis, kesesuaian dengan standar kompetensi, pemilihan strategi, pendekatan, dan metode; pemilihan sarana dan prasarana; kesesuaian dengan pembelajaran kooperatif tipe STAD; kesesuaian urutan materi, kesesuaian dengan alokasi dan waktu.

Perangkat pembelajaran ini layak dilakukan ujicoba dengan mendapatkan skor rata-rata dari penilaian validator dengan kriteria minimal valid dan Hasil uji coba menunjukan baik, dengan memenuhi kriteria sebagai berikut: a. Kemampuan guru mengelola pembelajaran tergolong efektif, b. Aktivitas siswa tergolong aktif, 
c. Kriteria positif untuk respon siswa terhadap pembelajaran dan ketuntasan hasil berlajar memenuhi kriteria tuntas dan (d) Tes hasil belajar memenuhi valid, reliable dan sensitive.

\section{HASIL PENELITIAN DAN PEMBAHASAN}

\section{Hasil Penelitian}

Proses pengembangan perangkat pembelajaran model kooperatif tipe STAD dengan media pembelajaran Microsoft PowerPoint Ispring mengikuti langkahlangkah model pengembangan 4-D yang dikemukakan oleh Thiagarajan. Keempat langkah tersebut adalah:

a. Define (Pendefinisian)

Tahap ini terdiri dari analisis awal-akhir, analisis siswa, analisis materi, analisis tugas, dan spesifikasi indikator hasil belajar. Pada tahap analisis awal-akhir diperoleh informasi tentang kurangnya penggunaan media dalam proses pembelajaran serta kurang menunjangnya buku paket dan LKS yang digunakan oleh siswa. Pada tahap analisis siswa diperoleh jumlah siswa Kelas VII SMP Muhammadiyah 13 adalah 65 siswa yang dibagi dalam dua kelas pararel. Usia mereka di antara 11- 15 tahun. Berdasarkan hasil belajar tengah semester I tahun pelajaran 2013-2014 dari 66 siswa hanya 47,48\% siswa yang mencapai ketuntasan belajar dengan KKM yang dtetapkan di sekolah tersebut. Dalam melakukan analisis materi, peneliti memperhatikan standar kompetensi dan kompetensi dasar pada pokok bahasan Segiempat (Jajargenjang, Layang-layang dan trapesium) sehingga diperoleh serangkaian tugas yang akan dikerjakan oleh siswa dan spesifikasi indikator pencapaian hasil belajar sesuai dengan tujuan pembelajaran. Hasil rincian indikator yang ditetapkan yaitu (1) Menuliskan pengertian jajar genjang, layanglayang dan trapesium, (2) Menuliskan sifat-sifat jajargenjang, layang-layang dan trapesium, (3) Menemukan dan menuliskan rumus luas dan keliling jajargenjang, layang-layang dan trapesium dan (4) Menyelesaikan persoalan yang berkaitan dengan sifat-sifat, pengertian, luas dan keliling jajargenjang, layang-layang dan trapezium 


\section{b. Design (Perancangan)}

Tahap ini terdiri dari pemilihan media, pemilihan format, dan perancangan awal perangkat pembelajaran. Pada tahap pemilihan media, peneliti menentukan media yang digunakan antara lain papan tulis, Media Power Point Ispring, LCD, dan kertas Karton. Pemilihan media ini disesuaikan dengan karakteristik siswa dan materi serta fasilitas-fasilitas yang disediakan di sekolah tersebut. Pada tahap pemilihan format, pengembangan RPP disesuaikan dengan format RPP pada kurikulum tingkat satuan pendidikan 2006. Format LKS dibuat dengan ilustrasi gambar dan berwarna untuk menarik perhatian siswa. Hasil rancangan awal perangkat pembelajaran diperoleh RPP, LKS dan Kuis untuk Tiga kali pertemuan serta diperoleh instrumen tes hasil belajar yakni THB.

\section{c. Develop (Pengembangan)}

Tahap ini terdiri dari uji validasi ahli dan uji coba lapangan. Hasil uji validasi oleh para ahli untuk perangkat pembelajaran dinyatakan baik dengan sedikit revisi dan layak digunakan. Setelah dilakukan revisi kecil peneliti melakukan uji keterbacaan dan uji coba lapangan untuk mengetahui baik tidaknya perangkat yang telah dikembangkan. Hasil dari uji keterbacaan, perangkat pembelajaran tidak perlu direvisi.

\section{d. Disseminate (penyebaran)}

Tahap ini terdiri dari uji validasi, pengemasan, difusi dan adopsi. Uji validasi dilakukan pada saat peneliti melakukan presentasi hasil penelitian. Pada tahap pengemasan perangkat pembelajaran dikemas secara sederhana untuk dapat dimanfaatkan di sekolah tempat dilakukan penelitian juga dapat digunakan bagi orang lain yang akan melakukan penelitian serupa

\section{Pembahasan}

Berdasarkan hasil penelitian yang telah diuraikan, maka pada bagian ini akan dibahas hasil penelitian sebagai berkut:

\section{Perangkat Pembelajaran}

Berdasarkan hasil pada tahap validasi ahli menunjukkan bahwa perangkat pembelajaran model kooperatif tipe STAD pada materi jajargenjang, layang-layang dan trapesium yang terdiri dari: Rencana Pelaksanaan Pembelajaran (RPP), Lembar 


\section{Endang Suprapti}

Kegiatan Siswa (LKS), Kuis dan Tes Hasil Belajar (THB) ditinjau dari indikator format, bahasa, isi, dan/atau ilustrasi dikategorikan baik dengan sedikit revisi. Hal ini ditunjukkan dengan rata-rata penilaian dari para validator terhadap masingmasing RPP dan LKS berada pada kategori baik dan sangat baik. Sedangkan hasil penilaian para validator terhadap THB secara umum adalah valid, dapat dipahami, dan dapat digunakan dengan sedikit revisi. Sedangkan Media Pembelajaran Microsoft Powerpoint Ispring ditinjau dari asepek kesederhanaan, keterpaduan, penekanan dan keseimbangan serta bentuk memiliki rata-rata baik dengan revisi kecil begitu juga ditinjau dari aspek format, isi dan bahasa memenuhi kategori baik, hal ini ditunjukan dengan rata-rata setiap aspek berada pada tingkatan baik.

Pada tahap uji keterbacaan, para siswa menyatakan LKS dan THB dapat dibaca dan dipahami dengan jelas. Sedangkan guru mitra menyatakan bahwa RPP yang dikembangkan dapat dipahami maksud dan tujuan dari setiap kalimat yang tertera. Dengan demikian, perangkat pembelajaran pada tahap uji keterbacaan tidak ada perlu direvisi.

Berdasarkan hasil pada tahap uji coba untuk pertemuan satu sampai ketiga diperoleh aktivitas siswa dalam pembelajaran efektif, kemampuan guru mengelola pembelajaran efektif, respons siswa positif, dan THB dinyatakan valid, reliabel, dan sensitif.

Dengan demikian, berdasarkan hasil pada tahap validasi ahli, uji keterbacaan, dan uji coba dihasilkan perangkat pembelajaran yang sudah memenuhi kriteria perangkat pembelajaran yang baik untuk pembelajaran model kooperatif tipe STAD dengan Media Microsoft PowerPoint Ispring pada materi jajar-genjang, layang-layang dan trapezium

\section{Kemampuan Guru Mengelola Pembelajaran}

Berdasarkan hasil analisis data, menunjukkan bahwa nilai rata-rata kemampuan guru mengelola pembelajaran untuk setiap kegiatan pembelajaran berada pada rentang nilai 3-4 Hal ini berarti kemampuan guru dalam mengelola pembelajaran kooperatif tipe adalah baik. Keberhasilan guru dalam mengelola pembelajaran kooperatif tipe STAD dikarenakan adanya perangkat pembelajaran yang dikembangkan oleh peneliti yang berupa RPP, LKS, dan THB dan media 
Microsoft Powerpoint Ispring. Kejelasan kegiatan guru dan siswa pada RPP dan LKS sangat menentukan terlaksananya proses pembelajaran yang sesuai dengan model pembelajaran yang diterapkan. Guru selalu berkeliling untuk mengawasi kinerja siswa dalam kelompok. Guru memberikan bimbingan dengan menggunakan Scafollding kepada siswa/kelompok yang mengalami kesulitan menyelesaikan LKS (terlihat pada gambar 3.1). Guru menyadari bahwa siswa belum terbiasa menyelesaikan masalah berbentuk cerita, oleh karena itu guru selalu berkeliling mengawasi siswa sekaligus memberikan bantuan jika ada siswa/kelompok merasa kesulitan. Selain itu keberhasilan guru dalam mengelola pembelajaran ini adalah dengan adanya diskusi antara peneliti dengan guru mitra tentang langkah-langkah pembelajaran dalam RPP dan memberikan masukan untuk perbaikan pembelajaran pada pertemuan selanjutnya

\section{Aktivitas Siswa dalam Pembelajaran}

Berdasarkan hasil analisis data diperoleh kesimpulan bahwa aktivitas siswa dalam pembelajaran adalah efektif. Menurut Eggen dan Kauchak (1996: 1) semakin tinggi keaktifan siswa semakin efektif pembelajaran yang dilaksanakan. Siswa dikatakan aktif jika melakukan aktivitas seperti mengejakan LKS, menjawab pertanyaan atau menjelaskan kepada guru atau teman, dan bertanya baik kepada guru maupun teman. Sedangkan siswa dikatakan pasif jika mendengarkan penjelasan dari guru maupun teman (Leiken \& Zaslavsky dalam Suradi, 2005). Dari data yang diperoleh terlihat bahwa jumlah persentase siswa aktif (seperti yang dikemukakan di atas) lebih besar dari pada jumlah persentase siswa pasif. Berdasarkan analisis deskriptif diperoleh kesimpulan bahwa aktivitas siswa dalam pembelajaran adalah efektif. Hal ini menunjukkan bahwa pembelajaran dengan perangkat pembelajaran yang berorientasi pada pembelajaran kooperatif tipe STAD dapat meningkatkan aktifitas siswa yang aktif dan mengurangi dominasi guru dalam proses pembelajarannya. Aktivitas siswa yang dominan yang dilakukan selama pembelajaran adalah diskusi menyelesaikan tugas dalam LKS dan mempresentasikan hasil diskusi di depan kelas. Hal ini berdasarkan hasil pengamatan oleh pengamat selama 3 pertemuan. Kurangnya dominasi guru dalam menjelaskan suatu materi membuat siswa mempunyai banyak waktu untuk 


\section{Endang Suprapti}

berdiskusi dengan kelompoknya masing-masing. Hal ini didukung oleh data aktivitas siswa untuk tiap aspek berada pada kriteria waktu yang ideal. Selama pembelajaran, siswa antusias mengikuti kegiatan diskusi menyelesaikan LKS. Siswa dalam kelompok saling membantu menuntaskan tugas dalam LKS. Selain itu, siswa juga lebih berani dan aktif untuk bertanya mengenai kesulitan yang dialami saat mengerjakan LKS.

\section{Respon Siswa}

Hasil analisis respons siswa mengenai proses pembelajaran dengan menggunakan model pembelajaran kooperatif tipe STAD dengan Media Powerpoint ISpring ini menunjukkan bahwa lebih dari 94\% siswa menyatakan respon positif terhadap proses pembelajaran maupun perangkat pembelajaran. Respon positif dari siswa memberikan petunjuk bahwa pembelajaran tersebut dapat membuat siswa senang dan antusias dalam pembelajaran serta siswa dapat menerima model pembelajaran kooperatif tipe STAD, sehingga diharapkan siswa dapat memperoleh hasil belajar yang lebih baik.

\section{Hasil Belajar Siswa}

Berdasarkan skor ketuntasan belajar minimal (SKBM) yang ditetapkan pada kurikulum KTSP yang menyatakan bahwa ketuntasan belajar secara klasikal apabila di kelas tersebut terdapat $\geq 85 \%$ siswa telah tuntas belajar, maka hasil belajar siswa yang mengikuti pembelajaran kooperatif tipe STAD dengan median Microsoft Powerpoint Ispring sudah tercapai karena di kelas tersebut terdapat $\geq$ $85 \%$ siswa yang telah tuntas belajar. Dari data postest menunjukkan bahwa 4 siswa dari 30 atau 86,6\% siswa pada kelas ujicoba tuntas belajar. Hal ini menunjukkan bahwa hasil belajar siswa yang mengikuti pembelajaran dengan menggunakan Perangkat Pembelajaran kooperatif tipe STAD dengan Media Microsoft Powerpoint Ispring Efektif Hal ini sesuai dengan penelitian penelitian yang dilakukan oleh Didik Dwi Widodo (2011) juga menunjukkan pembelajaran model kooperatif tipe STAD dengan Penggunaan modul efektif, memberikan pengaruh yang baik terhadap prestasi belajar dan kemampuan siswa. 


\section{SIMPULAN}

Berdasarkan Hasil dari uji coba lapangan diperoleh kesimpulan bahaw perangkat pembelajaran yang telah dikembangkan oleh penelti telah memenuhi kriteria perangkat pembelajaran yang baik karena dari hasil penelitian telah memenuhi syarat-syarat antara lain: (1)Valid yaitu telah divalidasi oleh ahli dan memenuhi kriteria Valid, (2) Setelah ujicoba coba, dengan memenuhi kriteria sebagai berikut: (a) Kemampuan guru mengelola pembelajaran tergolong efektif (b) Aktivitas siswa tergolong aktif. (c) Respon siswa terhadap pembelajaran memenuhi kriteria positif dan ketuntasan belajar memenuhi kriteria tuntas (d) Tes hasil belajar memenuhi valid, reliable dan sensitive.

\section{DAFTAR PUSTAKA}

Arends, Richard I., 1997. Classroom Instruction and Management. McGraw-Hill. Arikunto, Suharsimi. 2001. Dasar-dasar Evaluasi Pendidikan. Jakarta: Bumi Aksara. , 2000. Manajemen Penelitian. Jakarta: Rineka Cipta.

Arsyad, Azhar. 2010. Media Pembelajaran. Jakarta: Rajawali Pers.

Didik Dwi Widodo, 2011, Pengembangan Perangkat Pembelajaran Kooperatif tipe STAD dengan Modul untuk pokok bahasan Sistem Persamaan Linier tiga Peubah, Tesis Tidak di Publikasikan. Surabaya: Program Pasca Sarjana Universitas Negeri Surabaya.

HUdojo, Herman, 1988. Mengajar Belajar Matenatika. Jakarta: Departemen Pendidikan Nasional

Ibrahim, Muslimin, dkk. 2000. Pembejaran Kooperatif, University Press. Universitas Negeri Surabaya

Isjoni, 2007. Pembelajaran Kooperatif. Yogyakarta: Pustaka Pelajar.

Khabibah, Siti, 2006. Pengembangan Model Pembelajaran Matematika dengan soal terbuka untuk meningkatkan kreatifitas siswa sekolah Dasar. Disertasi, Tidak di Publikasikan. Surabaya: Program Pasca Sarjana Universitas Negeri Surabaya.

Mulyasa E, 2007, Standar Kompetensi dan Sertifikasi Guru, Bandung: PT. Rosda Karya

Munadi, Yudhi, 2008, Media Pembelajaran, Jakarta: Gaung Persada

Nur, M. 2005. Pembelajaran Kooperatif. Surabaya: UNESA University Press

Pribadi, Benny A, 2009. Model Disain Sistem Pembelajaran, Jakarta: Dian Rakyat Ratumanan, Tanwey G, 2004, Belajar dan Pembelajaran, Surabaya: UNESA University Press

Riyanto Yatim, 2005. Paradigma Pembelajaran. Surabaya: UNESA University Press

--------, 2006. Pengembangan Kurikulum dan Seputar Kurikulum Tingkat Satuan Pendidikan. Surabaya: UNESA University Press 
Sadiman Arief S, dkk. 2009. Media Pendidikan, Jakarta: PT GRafindo Persada Sagala saiful, 2009. Konsep dan Makna Pembelajaran. Bandung: Alfabeta.

Sistem Informasi UKDW, 2005. Tutorial Microsoft PowerPoint, www2.ukdw.ac.id/kuliah/si/SI4012/materi/pp.pdf diaccess tanggal 22 Juli 2014, Pukul 21.15

Slavin, Robert E. 2009. Cooperative Learning. Bandung: Nusa Media

Slavin, R.E, 1994. Educational Psychology Theory Into Practices (Fourth Edition). Boston: Allyn and Bacon

Soedjadi R 2000, Kiat Pendidikan Matematika di Indonesia. Jakarta: Departemen Pendidikan Nasional

Thiagarajan, S., Semmel, D.S., dan Semmel, M.I. 1974. Intructional Development for Training Teachers of Exceptional Children. Minnesota: University of Minnesota.

Trianto. 2007. Model-model Pembelajaran Inovatif Berorientasi Konstruktivistik. Jakarta: Prestasi Pustaka.

Veronita Libra Kusumawati, Enny, 2012, Pengembangan Perangkat Pembelajaran Kooperatif tipe STAD untuk materi Barisan dan Deret Kelas IX SMK Negeri 4 Surabaya, Tesis Tidak di Publikasikan. Surabaya: Program Pasca Sarjana Universitas Negeri Surabaya.

Yamasari, Yuni, 2010. Pengembangan Media Pembelajaran Matematika Berbasis ICT yang berkualitas. Seminar Nasional Pasca Sarjana X-ITS, Surabaya 4 Agustus 2010, ISBN No. 979-545-0270-1. 